\title{
Correction to: A protocol for umbilical cord tissue cryopreservation as a source of mesenchymal stem cells
}

\author{
Diego Raffo ${ }^{1,2}$ [ $\cdot$ Andrea Maglioco ${ }^{3,4} \cdot$ Diego Fernandez Sasso $^{1}$
}

Published online: 19 February 2021

(c) Springer Nature B.V. 2021

\section{Correction to: Molecular Biology Reports https://doi.org/10.1007/s11033-020-06079-x}

The author names were interchanged in the original article. They should read as follows Diego Raffo, Andrea Maglioco and Diego Fernadez Sasso.

The original article has been corrected.

Publisher's Note Springer Nature remains neutral with regard to jurisdictional claims in published maps and institutional affiliations.

The original article can be found online at https://doi.org/10.1007/ s11033-020-06079-x.

\section{Diego Raffo}

draffo@cedie.org.ar

1 Criocenter SRL, Buenos Aires, Argentina

2 Centro de Investigaciones Endocrinológicas “Dr. César Bergadá" (CEDIE), CONICET - FEI - División de

Endocrinología, Hospital de Niños R. Gutiérrez,

Buenos Aires, Argentina

3 Universidad Abierta Interamericana (UAI), Centro de Altos Estudios en Ciencias Humanas y de la Salud (CAECIHS), Buenos Aires, Argentina

4 Consejo Nacional de Investigaciones Científicas y Técnicas (CONICET), Buenos Aires, Argentina 